\title{
Modification of the activity of an $\alpha$-amylase from Bacillus licheniformis by several surfactants
}

\author{
Vicente Bravo Rodríguez* \\ Departamento de Ingeniería Química \\ Universidad de Granada \\ Avd. Fuentenueva s $/ \mathbf{n}$ \\ 18071 Granada, Spain \\ Tel: 34958243310 \\ Fax: 34958248992 \\ E-mail: vbravo@ugr.es
}

\section{Encarnación Jurado Alameda \\ Departamento de Ingeniería Química \\ Universidad de Granada \\ Avd. Fuentenueva s/n \\ 18071 Granada, Spain \\ Tel: 34958243307 \\ Fax: 34958248992 \\ E-mail: ejurado@ugr.es}

Juan Francisco Martínez Gallegos

Departamento de Ingeniería Química

Universidad de Granada

Avd. Fuentenueva s $/ \mathbf{n}$

18071 Granada, Spain

Tel: 34958243314

Fax: 34958248992

E-mail: jfmart@ugr.es

\section{Antonia Reyes Requena}

Departamento de Ingeniería Química

Universidad de Granada

Avd. Fuentenueva s $/ \mathrm{n}$

18071 Granada, Spain

Tel: 34958249018

Fax: 34958248992

E-mail: areyesr@ugr.es

Ana Isabel García López

Departamento de Ingeniería Química

Universidad de Granada

Avd. Fuentenueva s $/ \mathrm{n}$

18071 Granada, Spain

Tel: 34958249018

Fax: 34958248992

E-mail: vbravo@ugr.es

Joaquim Manuel Sampaio Cabral

Centro de Engenharia Biológica e Química Instituto Superior Técnico

Universidade Técnica de Lisboa Av. Rovisco Pais

1049-001 Lisboa, Portugal

Tel: 351218419063

Fax: 351218419062

E-mail: joaquim.cabral@ist.utl.pt

\section{Pedro Fernandes}

Centro de Engenharia Biológica e Química Instituto Superior Técnico

Universidade Técnica de Lisboa

Av. Rovisco Pais

1049-001 Lisboa, Portugal 
Bravo Rodríguez, V. et al.

\author{
Tel: 351218419189 \\ Fax: 351218419062 \\ E-mail: pedro.fernandes@mail.ist.utl.pt \\ Luis Joaquim Pina da Fonseca \\ Centro de Engenharia Biológica e Química \\ Instituto Superior Técnico \\ Universidade Técnica de Lisboa \\ Av. Rovisco Pais \\ 1049-001 Lisboa, Portugal \\ Tel: 351218419139 \\ Fax: 351218419062 \\ E-mail: 1fonseca@alfa.ist.utl.pt
}

Financial support: Fellowship awarded to Juan Francisco Martínez Gallegos by Spanish Ministry of Science and Education, FPU fellowships program.

Keywords: $\alpha$-amylase, alkyl polyglycosides, enzymatic activity, fatty alcohol ethoxylates, linear alkyl benzene sulfonate, nonyl phenol ethoxylate.

\author{
Abbreviations: AE: enzymatic activity without surfactant \\ $\mathrm{AE}_{\mathrm{T}}$ : enzymatic activity in presence of surfactant \\ AER: relative enzymatic activity \\ CMC: critical micelle concentration \\ HLB: Hydrophilic Lipophilic Balance \\ KNU: Kilo Novo Unit \\ LAS: linear alkyl benzene sulfonate \\ NU: Novo Unit \\ SDS: sodium dodecyl sulphate
}

The influence of different commercial surfactants on the enzymatic activity of a commercial $\alpha$-amylase from Bacillus licheniformis (Termamyl $300 \mathrm{~L}$ ) has been studied. As non-ionic surfactants, alkyl polyglycosides (Glucopon ${ }^{\circledR}$ 215, Glucopon ${ }^{\circledR} 600$ and Glucopon ${ }^{\circledR}$ 650) were studied, as were fatty alcohol ethoxylates (Findet 1214N/23 and Findet 10/15), and nonyl phenol ethoxylate (Findet 9Q/21.5NF). Also, an anionic surfactant, linear alkyl benzene sulfonate (LAS) was assayed. In general, none of the non-ionic surfactants studied, except Findet 10/15, vary substantially the enzymatic activity. Findet $10 / 15$ has the strongest hydrophobic character and reduces the enzymatic activity more significantly the greater its concentration. Regarding LAS, this surfactant significantly depressed enzymatic activity, presumably due to the electrostatic interactions caused by its anionic character.

Nowadays, amylases ( $\alpha$-amylases, $\beta$-amylases and glucoamylases) represent one of the most important enzyme groups within the field of biotechnology. These enzymes are present in numerous biotechnological and industrial applications, including their use in detergent formulations (Tanaka and Hoshino, 1999). The use of enzymes in detergents offers multiple advantages from an environmental standpoint: energy savings on using lower washing temperatures, replacement or reduction of other more environmentally harmful components, lack of negative effects on the sewage-water-treatment systems, and absence of risk for aquatic wildlife.
One of the main problems affecting the action of these enzymes in detergent formulations is the possible influence of surfactants on enzymatic hydrolysis, due to possible interactions of the surfactant both with the reaction substrate as well as with the enzyme.

With respect to the substrate, in the case of starch, it is known that amylose, mainly, and to a lesser extent amylopectin can interact with surfactants, giving rise to inclusion complexes (Svensson et al. 1996; Lundqvist et al. 2002a; Lundqvist et al. 2002b; Lundqvist et al. 2002c; Tanaka and Hoshino, 2002; Hoshino and Tanaka, 2003). The formation of these complexes between the surfactants and starch can hamper their enzymatic hydrolysis with amylases; thus, it has been confirmed that the formation of surfactant complexes with amylose hinders enzymatic hydrolysis with $\beta$-amylase, being only partially hydrolysable (Kim and Robinson, 1979).

With regard to the enzyme, many surfactants that interact with proteins can present in their structure different electrical charges and different hydrophobic and hydrophilic groups which alter the secondary and tertiary structures of proteins. In particular, many enzymes are unstable in solutions of anionic surfactants such as sodium dodecyl sulphate (SDS), sodium dodecyl benzene sulfonate and sodium ether sulphate (Tanaka and Hoshino, 1999; Tanaka and Hoshino, 2002). In addition, the formation of micelles can also affect enzymatic kinetics. It has been demonstrated that the hydrolysis rates of amylose by $\alpha$ amylase from Bacillus amyloliquefaciens and Bacillus licheniformis vary in the presence of SDS; the reaction rate

* Corresponding authors 
increases at concentrations lower than the critical micelle concentration of the surfactant and decreases over this level, this effect being less pronounced on the enzyme from Bacillus licheniformis than on the enzyme from Bacillus amyloliquefaciens (Tanaka and Hoshino, 2002).

Table 1. Critical micelle concentration, hydrophilic-lipophilic balance, and moisture content of the different commercial surfactants assayed.

\begin{tabular}{|c|c|c|c|}
\hline Surfactant & $\begin{array}{c}\text { CMC } \\
\text { (g/L) }\end{array}$ & HLB $^{(1)}$ & H (\%) \\
\hline Glucopon 215 & 0.241 & 13 & $37.0^{(1)}$ \\
\hline Glucopon 600 & 0.028 & 11.2 & $46.6^{(1)}$ \\
\hline Glucopon 650 & 0.073 & 11.9 & $50.4^{(1)}$ \\
\hline Findet 10/15 & 0.152 & 9.6 & $0.423^{(1)}$ \\
\hline Findet 1214N/23 & 0.021 & 14.4 & $0.309^{(1)}$ \\
\hline Findet 9Q/21.5NF & 0.034 & 12.8 & 1.4 \\
\hline LAS & 1.018 & - & $0^{(2)}$ \\
\hline
\end{tabular}

(1) Data obtained from the results of Bravo Rodríguez et al. (2005) (2) Data provided by the manufacturer.

In addition, some enzymes are more stable in the presence of non-ionic surfactants than in the presence of anionic surfactants. The formation of micelles of anionic surfactants can alter the conformation of the protein due to the existence of strong electrostatic and hydrophobic interactions between the micelles and the proteins (Montserret et al. 2000; Hagihara et al. 2002). On the contrary, non-ionic surfactants do not alter the conformation of the protein, since they do not cause any electrostatic interaction (Russell and Britton, 2002) and, moreover, some non-ionic surfactants increase the catalytic activity of enzymes. On studying the effect of the non-ionic surfactant polyoxyethylene mono-N-dodecyl ether (Brij 35) on the enzymatic hydrolysis of amylopectin from potato with an $\alpha$-amylase from Bacillus amyloliquefaciens, it was found that the reaction rate raised with an increasing concentration of the surfactant above its critical micelle concentration while the non-aggregated surfactant molecules did not boost the reaction rate (Hoshino and Tanaka, 2003). It has been shown that amylopectin binds to surfactant and that enzyme binds to the micelles of the surfactant in such a way that the catalysis appears to be more efficient in the micellar pseudophase than in the aqueous pseudophase. This most likely results from the high enzyme and amylopectin concentrations in the micellar pseudophase. Also, it has been verified that fatty alcohol ethoxylates stabilize proteases in the presence of anionic surfactants such as LAS, thereby preventing the loss of the enzymatic activity (Russell and Britton, 2002). Finally, it should be highlighted that the alkyl polyglycosides are capable of increasing enzyme stability (proteases, lipases, amylases, and cellulases) in liquiddetergent formulations, impeding the loss of activity during detergents storage (Von Rybinski and Hill, 1998).

When these facts are taken into account, it becomes evident that in order to effectively use $\alpha$-amylases in detergent formulations it is necessary to study the effect that different surfactants can cause in its enzymatic activity. In the present work, the influence of several non-ionic surfactants, alkyl polyglycosides, fatty alcohol ethoxylates, and nonyl phenol ethoxylate is studied in relation to the activity of a commercial $\alpha$-amylase, comparing them with a classical anionic surfactant, linear alkyl benzene sulfonate (LAS).

\section{MATERIALS AND METHODS}

An $\alpha$-amylase of bacterial origin (Bacillus licheniformis) from Novozymes A/S, Termamyl ${ }^{\circledR} 300$ L Type DX was used. This enzyme is used specifically in detergent formulations for laundry and dishwashers. It presents an activity, according to the manufacturer, of $300 \mathrm{KNU} / \mathrm{g}$, where $1 \mathrm{KNU}$ (Kilo Novo Unit) is defined as the amount of enzyme which hydrolyses $4870 \mathrm{mg}$ (on a dry basis) of soluble Merck starch (Erg. B 6, lot number 6380528) per hour under standard conditions, $\mathrm{pH} 5.6,37^{\circ} \mathrm{C}$, and $\mathrm{Ca}^{2+}$ concentration $0.0003 \mathrm{M}$ (Novozymes A/S, 2001a).

As non-ionic surfactants, alkyl polyglycosides Glucopon ${ }^{\circledR}$ 215 CS UP, Glucopon ${ }^{\circledR} 600$ CS UP, and Glucopon ${ }^{\circledR} 650$ EC (from Cognis Deutschland $\mathrm{GmbH} \& \mathrm{Co}$ ) were used, as well as fatty alcohol ethoxylates, Findet 10/15 and Findet $1214 \mathrm{~N} / 23$ (Kao Corporation S.A.), and nonyl phenol (with 9.5 moles of ethylene oxide) under the commercial name of Findet 9Q/21.5NF (Kao Corporation S.A.). In addition, an anionic surfactant was used, LAS (linear alkyl benzene sulfonate), from Kao Corporation S.A.. Table 1 lists the critical micelle concentration values (CMC), hydrophiliclipophilic balance (HLB), and initial moisture content of the commercial surfactant $(\mathrm{H}, \% \mathrm{w} / \mathrm{w})$, for each surfactant. The CMC values were established by measuring the surface tension of surfactant solutions with different concentrations at $37^{\circ} \mathrm{C}$, using a tensiometer model Tensiometer $\mathrm{K} 11$ (KRÜSS $\mathrm{GmbH}$ ) equipped with a $2 \mathrm{~cm}$ platinum plate. The moisture content of Findet $9 \mathrm{Q} / 21.5 \mathrm{NF}$ was determined from two dried samples in an infrared balance, model AD4714A (A\&D Co., Ltd.), at $102^{\circ} \mathrm{C}$ for $30 \mathrm{~min}$.

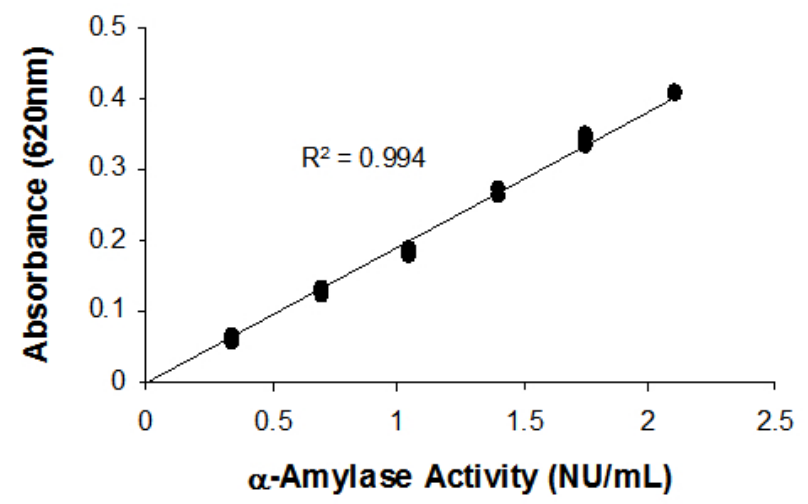

Figure 1. Standard calibration curve for the $\alpha$-amylase activity with Phadebas $®$ tablets.

To determine the activity of the $\alpha$-amylase in the presence of the surfactants, a standard method was used (Novozymes A/S, 2001b) based on the kit Phadebas ${ }^{\circledR}$ Amylase Test from 
Table 2. Surfactant concentration, enzymatic activity in the presence of surfactant (mean of duplicated experiments), enzymatic activity in the absence of surfactant (mean of duplicated experiments), relative enzymatic activity (mean of duplicated experiments) and corresponding standard deviation, for the different commercial surfactants assayed.

\begin{tabular}{|c|c|c|c|c|c|}
\hline & $\mathrm{pH}=7.3$ & & $\mathrm{~T}=37^{\circ} \mathrm{C}$ & & \\
\hline Surfactant & $\mathrm{C}(\mathrm{g} / \mathrm{L})$ & $\mathrm{AE}_{\mathrm{T}}(\mathrm{NU} / \mathrm{ml})$ & $\mathrm{AE}(\mathrm{NU} / \mathrm{ml})$ & $\mathrm{AER}(\%)$ & $\mathrm{STDV}(\%)$ \\
\hline Findet 1214N/23 & 0.060 & 1.68 & 1.78 & 94.6 & 0.6 \\
\hline Findet 1214N/23 & 0.060 & 1.66 & 1.78 & 93.2 & 1.1 \\
\hline Findet 1214N/23 & 0.006 & 1.75 & 1.79 & 97.5 & 0.6 \\
\hline Findet 1214N/23 & 0.006 & 1.74 & 1.78 & 97.8 & 0.0 \\
\hline Findet 10/15 & 1.0 & 0.70 & 1.75 & 40.1 & 0.5 \\
\hline Findet 10/15 & 0.2 & 1.36 & 1.75 & 77.5 & 0.0 \\
\hline Findet 9Q/21.5NF & 0.025 & 1.53 & 1.67 & 91.3 & 2.8 \\
\hline Findet 9Q/21.5NF & 0.015 & 1.51 & 1.67 & 89.7 & 0.3 \\
\hline Glucopon 215 & 1.2 & 1.86 & 1.75 & 106.2 & 3.4 \\
\hline Glucopon 215 & 0.6 & 1.79 & 1.75 & 101.9 & 0.8 \\
\hline Glucopon 600 & 0.10 & 1.89 & 1.75 & 108.0 & 1.6 \\
\hline Glucopon 600 & 0.05 & 1.88 & 1.75 & 107.5 & 0.0 \\
\hline Glucopon 650 & 0.3 & 1.79 & 1.75 & 102.4 & 5.6 \\
\hline Glucopon 650 & 0.1 & 1.79 & 1.75 & 102.5 & 4.6 \\
\hline LAS & 0.8 & 1.06 & 1.04 & 63.1 & 0.2 \\
\hline LAS & 0.2 & & 1.67 & 3.7 \\
\hline
\end{tabular}

PHARMACIA Diagnostics AB. This method uses Phadebas $^{\circledR}$ tablets as reaction substrate, which contains an insoluble coloured starch complex that releases soluble blue fragments when hydrolysed by the $\alpha$-amylase. The colour can be measured spectrophotometrically at $620 \mathrm{~nm}$, the absorbance measured being a function of the enzymatic activity (Ceska et al. 1969). Taking as a reference an enzyme of known activity enables the calculation of the enzymatic activity in the presence or absence of surfactants. For this a standard calibration curve of Termamyl solutions with different enzymatic activity was made (Figure 1), under the experimental conditions $37^{\circ} \mathrm{C}$ and $\mathrm{pH}$ 7.3.

The relative enzymatic activity, AER, was defined as the quotient between the activity in the presence of the surfactant, $\mathrm{AE}_{\mathrm{T}}$, and the activity in its absence, $\mathrm{AE}$. For each surfactant, the relative activity of the enzyme was measured at two different concentrations. Duplicate runs, at least, were performed in each case.

\section{RESULTS AND DISCUSSION}

Table 2 lists the mean enzymatic activities of each duplicated experiment in the presence and absence of the surfactant, as well as the mean value of the resulting relative enzymatic activity for each duplicated assay together with its standard deviation (STDV) for each of the concentrations of the commercial surfactants assayed.

First, four duplicated experiments were performed with
Findet $1214 \mathrm{~N} / 23$, two at concentrations above its CMC and another two at concentrations below its CMC (Table 2). The mean AER is slightly higher at concentrations below the $\mathrm{CMC}$, when matched to the AER at concentrations above the $\mathrm{CMC}$, the reverse situation to that described by other authors, who reported an increase in the reaction rate at concentrations above the CMC for non-ionic surfactants (Hoshino and Tanaka, 2003). Nevertheless, it should be pointed out that the differences between the mean AER values at concentrations above and below the $\mathrm{CMC}$ are very small, these values also being very close to $100 \%$; it can therefore be concluded that the fatty alcohol ethoxylate Findet $1214 \mathrm{~N} / 23$ does not significantly affect the enzymatic activity.

The next surfactant studied was another fatty alcohol ethoxylate Findet 10/15 (Table 2). Given that in the case of Findet $1214 \mathrm{~N} / 23$ no significant differences were detected between surfactant concentrations above and below the $\mathrm{CMC}$, only experiments at surfactant concentrations higher than its CMC were made. With Findet 10/15, very significant losses in enzymatic activity are noted and this loss in activity increases with the concentration of the surfactant. This situation was not foreseeable, since this is a non-ionic surfactant, which has no electrostatic interactions with the enzyme, and being known the capacity of the fatty alcohol ethoxylates to stabilize proteases in the presence of anionic surfactants (Russell and Britton, 2002). Thus such a sharp decline in the enzymatic activity was unexpected. However, it should be pointed out that Findet 10/15 
presents the lowest HLB of all non-ionic surfactants assayed, (Table 1). Also, its HLB is slightly lower than 10, that is, the lipophilic groups predominates over the hydrophilic ones, and thus its greater hydrophobic character may determine a greater interaction with the enzyme and hence a reduction in the enzymatic activity which is more significant as the surfactant concentration increases.

The last non-ionic ethoxylate surfactant studied was Findet 9Q/21.5F. Concentrations close to its CMC, but below this value (surfactants are usually used at concentrations under CMC but near to this value), were assayed showing a very slight loss of enzymatic activity in the presence of surfactant, which furthermore does not depend on the surfactant concentration used (Table 2).

In the case of alkyl polyglycosides, three surfactants were assayed: Glucopon ${ }^{\circledR} 215$, Glucopon ${ }^{\circledR} 600$, and Glucopon ${ }^{\circledR}$ 650 , the results of which are listed in Table 2. All these surfactants were assayed at concentrations above their corresponding $\mathrm{CMC}$, resulting in a slight increase in the enzymatic activity in all cases, in agreement with the work by Hoshino and Tanaka (2003). On the other hand, these results are the opposite of the observations with the fatty alcohol ethoxylates assayed. In any case, given that the increase in enzymatic activity that is observed in the presence of these alkyl polyglycosides is very small, it can be concluded that the latter do not significantly affect the activity of the $\alpha$-amylase tested.

Finally, the effect of LAS on the enzyme activity was studied, testing concentrations lower than its CMC (Table 2 ). It is found that LAS, apart from its now known capacity for destabilizing proteases (Russell and Britton, 2002), is also capable of significantly decreasing the activity of the $\alpha$-amylase studied, even at concentrations lower than its $\mathrm{CMC}$, as opposed to the results previously published with another anionic surfactant, SDS (Tanaka and Hoshino, 2002). This noteworthy loss in enzymatic activity is most likely due to the electrostatic interactions inherent to the anionic character of LAS.

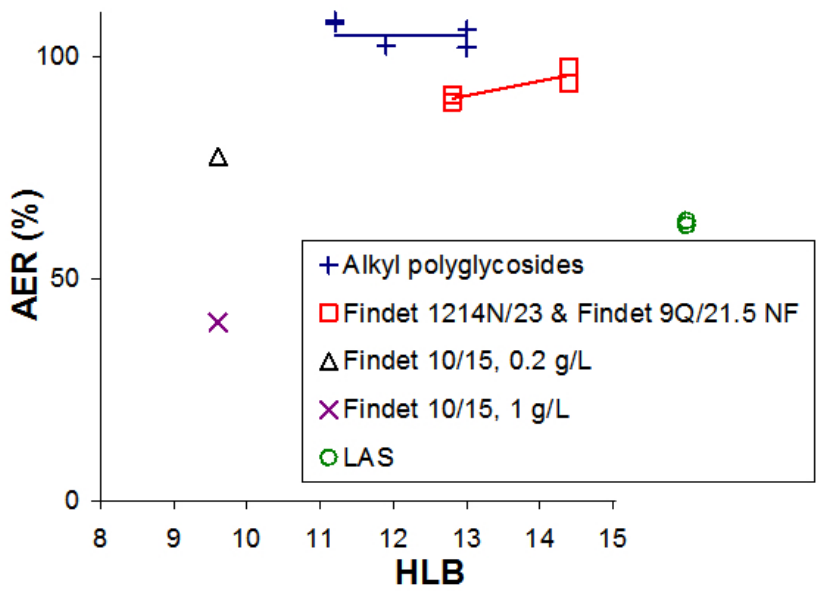

Figure 2. Influence of the HLB on the relative enzymatic Activity.
To conclude, the mean relative enzymatic activity for each surfactant concentration has been represented versus its HLB (Figure 2). In addition, it has been included, outside the HLB scale and for comparative purposes, the values corresponding to LAS. For alkyl polyglycosides, the enzymatic activity remains approximately constant and independent of the HLB value. On the contrary, considering the ethoxylate surfactants, the enzymatic activity declines on decreasing the HLB, in such a way that the less hydrophilic character of the nonyl phenol ethoxylate (Findet 9Q/21.5F) with respect to the Findet 1214N/23 could be the cause of the small loss in enzymatic activity detected in the assays made with Findet 9Q/21.5F (Table 2). Furthermore Brij 35 had been found to increase the hydrolytic rate of Bacillus amyloliquefaciens $\alpha$-amylase up to $65 \%$ when the surfactant was added at concentrations over $1.0 \%(\mathrm{wt} / \mathrm{vol})$, which is higher than its CMC (Hoshino and Tanaka, 2003). Bearing in mind that Brij 35 is a fatty alcohol ethoxylate with 12 atoms of carbon in its alkyl chain and 23 ethylene oxide moles per mol of surfactant, its HLB has also been calculated, obtaining a value 17.2. The HLB value of Brij 35 is higher than any of the ethoxylated surfactants assayed and, in agreement with the results obtained in the present work, it has the highest relative hydrolytic rate. For HLB values lower than 10, in the case of Findet 10/15, where the hydrophobic groups rules out in the molecule considered, there is a very significant loss of enzymatic activity, which in addition increases with the surfactant concentration.

From the results, it can be deduced that when $\alpha$-amylase from Bacillus licheniformis is to be used in detergent formulations, and from the standpoint of the possible alteration of its enzymatic activity, the most suitable surfactants to be included in these formulations would be alkyl polyglycosides, as they even tend to increase the activity somewhat. In the case of the ethoxylate surfactants studied a loss of enzymatic activity is observed, being more significant the lower the surfactant HLB value. This loss is proved to be significant also in the case of the classical anionic surfactant LAS.

\section{REFERENCES}

BRAVO RODRÍGUEZ, Vicente; JURADO ALAMEDA, Encarnación; REYES REQUENA, A.; GARCÍA LÓPEZ, Ana I.; BAILÓN-MORENO, Rafael and CUEVAS ARANDA, Manuel. Determination of average molecular weight of commercial surfactants: Alkylpolyglucosides and fatty-alcohol ethoxylates. Journal of Surfactants and Detergents, October 2005, vol. 8, no. 4, p. 341-346.

CESKA, Miroslav; BIRATH, Katarina and BROWN, Bette. A new and rapid method for the clinical determination of $\alpha$-amylase activities in human serum and urine. Optimal conditions. Clinica Chimica Acta, December 1969, vol. 26, no. 3, p. 437-444.

HAGIHARA, Yoshihisa; HONG, Dong-Pyo; HOSHINO, Masaru; ENJYOJI, Kei-ichi; KATO, Hisao and GOTO, Yuji. Aggregation of $\beta_{2}$-glycoprotein I induced by sodium 
lauryl sulfate and lysophospholipids. Biochemistry, January 2002, vol. 41, no. 3, p. 1020-1026.

HOSHINO, Eiichi and TANAKA, Atsushi. Enhancement of enzymatic catalysis of bacillus amyloliquefaciens $\alpha$ amylase by nonionic surfactant micelles. Journal of Surfactants and Detergents, October 2003, vol. 6, no. 4, p. 299-303.

KIM, Yoon J. and ROBINSON, Robert J. Effect of surfactants on starch in a model system. Starch/Stärke, September 1979, vol. 31, no. 9, p. 293-300.

LUNDQVIST, Henrik; NILSSON, Gunilla S.; ELIASSON, Ann-Charlotte and GORTON, Lo. Changing the amylopectin-sodium dodecyl sulphate interaction by modifying the exterior chain length. Starch/Stärke, April 2002a, vol. 54, no. 3-4, p. 100-107.

LUNDQVIST, Henrik; ELIASSON, Ann-Charlotte and OLOFSSON, Gerd. Binding of hexadecyltrimethylammonium bromide to starch polysaccharides. Part I. Surface tension measurements. Carbohydrate Polymers, July 2002b, vol. 49, no. 1, p. 4355 .

LUNDQVIST, Henrik; ELIASSON, Ann-Charlotte and OLOFSSON, Gerd. Binding of hexadecyltrimethylammonium bromide to starch polysaccharides. Part II. Calorimetric study. Carbohydrate Polymers, August 2002c, vol. 49, no. 2, p. 109-120.

MONTSERRET, Roland; MCLEISH, Michael J.; BÖCKMANN, Anja; GEOURJON, Christophe and PENIN, François. Involvement of electrostatic interactions in the mechanism of peptide folding induced by sodium dodecyl sulfate binding. Biochemistry, July 2000, vol. 39, no. 29 , p. $8362-8373$.

NOVOZYMES A/S. Determination of Alpha-Amylase Activity (KNU and FAU). Novozymes Analytical Method EB-SM-0009.02/01 [online], February 2001a [cited 3 July 2002]. Available from Internet: http://www.novozymes.com, from Novozymes A/S, Bagsvaerd, Denmark.

NOVOZYMES A/S. Determination of Alpha-Amylase Activity. Novozymes Analytical Method LUNA \# 200010338-01 [online], July 2001b [cited 3 July 2002]. Available from Internet: http://www.novozymes.com, from Novozymes A/S, Bagsvaerd, Denmark.

RUSSELL, Geoffrey L. and BRITTON, Larry N. Use of certain alcohol ethoxylates to maintain protease stability in the presence of anionic surfactants. Journal of Surfactants and Detergents, January 2002, vol. 5, no. 1, p. 5-10.

SVENSSON, Erik; GUDMUNDSSON, Magnus and ELIASSON, Ann-Charlotte. Binding of sodium dodecylsulphate to starch polysaccharides quantified by surface tension measurements. Colloids and Surfaces B:
Biointerfaces, May 1996, vol. 6, no. 4-5, p. 227-233.

TANAKA, Atsushi and HOSHINO, Eiichi. Study on the substrate specificity of $\alpha$-amylases that contribute to soil removal in detergents. Journal of Surfactants and Detergents, April 1999. vol. 2, no. 2, p. 193-199.

TANAKA, Atsushi and HOSHINO, Eiichi. Thermodynamic and activation parameters for the hydrolysis of amylose with Bacillus $\alpha$-amylases in a diluted anionic surfactant solution. Journal of Bioscience and Bioengineering, May 2002, vol. 93, no. 5, p. 485-490.

VON RYBINSKI, Wolfgang and HILL, Karlheinz. Alkyl polyglycosides-properties and applications of a new class of surfactants. Angewandte Chemie International Edition, June 1998, vol. 37, no. 10, p. 1328-1345. 